\title{
AVANÇO TECNOLÓGICO: OS DESAFIOS DA DEMOCRACIA BRASILEIRA NA ERA DA INTERNET
}

\author{
Ingrid Eduardo Macedo Barboza ${ }^{1}$
}

\begin{abstract}
RESUMO:
O trabalho analisa os desdobramentos que o recurso às tecnologias digitais de comunicação, na rede mundial de computadores, trouxe à democracia, partindo da percepção do ambiente virtual como espaço público de participação e interação social. A partir do surgimento das novas tecnologias de comunicação houve alteração na dinâmica do exercício da cidadania na sociedade brasileira? Foram utilizados método dedutivo e pesquisa bibliográfica. Em conclusão, com a internet não se cria novo modelo de democracia: a democracia digital. O espaço de atuação política é ampliado através de potencialidades que fomentam liberdade e igualdade popular no processo eleitoral e na gestão pública.
\end{abstract}

PALAVRAS-CHAVE: Democracia Digital; Cidadania; Internet; Participação Popular; Comunicação.

\section{TECHNOLOGICAL ADVANCEMENT: THE CHALLENGES OF BRAZILIAN DEMOCRACY IN THE ERA OF THE INTERNET}

\begin{abstract}
:
The work analyzes the developments that the use of digital communication technologies in the world wide web has brought to democracy, based on the perception of the virtual environment as a public space for participation and social interaction. Since the emergence of new communication technologies, has there been a change in the dynamics of the exercise of citizenship in Brazilian society? Deductive method and bibliographic research were used. In conclusion, with the internet, no new model of democracy is created: digital democracy. The space for political action is expanded through potentialities that foster freedom and popular equality in the electoral process and in public management.
\end{abstract}

KEY WORDS: Digital Democracy; Citizenship; Internet; Popular participation; Communication

\section{INTRODUÇÃO}

A democracia, desde seus primórdios, pressupõe a existência de um espaço público em que, com liberdade e igualdade, haja manifestações, debates, deliberações, bem como sejam tomadas decisões, em torno de uma pauta comum.

\footnotetext{
${ }^{1}$ Mestranda do Curso de Direito do Programa de Pós-Graduação da Universidade Federal do Ceará (UFC), Especialista em Direito Eleitoral e Processo Eleitoral pela Escola Superior da Magistratura do Estado do Ceará (ESMEC/CE), Servidora Efetiva do Tribunal Regional Eleitoral do Ceará (TRE/CE). Endereço eletrônico: ingrideduardo13@gmail.com.
} 
Esse "espaço público", a depender do momento histórico e das características das civilizações em que a democracia se estabeleceu, teve suas variações. Por exemplo, em Atenas, na Grécia, os "cidadãos"2 tinham, na "ágora", igual voz e direito a voto na hora de decidir por eles próprios o seu destino, sem embargo das discussões em torno de eventual anacronismo entre o conceito de democracia ateniense e a praticada a partir do advento da sociedade moderna.

Outra forma de manifestação popular, no "espaço público" está materializada no voto. De fato, a origem do voto remonta a períodos bem longínquos da civilização. Todavia, esse direito apenas foi à parcela mais ampla da população por volta do século XVIII, quando, em especial, no ocidente, passou-se a adotar a democracia representativa. Segundo esse regime, a soberania popular é exercida indiretamente, por representantes de governo escolhidos mediante eleição. O povo participa do processo de escolha dos governantes através do voto. Por sua vez, os representantes, em tese, imbuídos dos mesmos sentimentos dos representados devem implementar os interesses do corpo social.

Ao longo do tempo, espaços públicos de manifestação popular, de interação entre cidadão e governantes vêm se desenvolvendo. No Brasil, é possível citar, no âmbito da própria Administração Pública, as experiências promovidas por meio das audiências públicas. Além disso, podem ser citados outros ambientes externos, como os culturais, que se revelam através das músicas, poesias, pinturas, desenhos, literatura e cinema, assim como, os educacionais, os profissionais, as organizações de classes e as não governamentais, bem como as manifestações de rua que se evidenciam, até mesmo, através dos "panelaços", que se tornam cada vez mais frequentes. A internet também pode ser considerada um desses espaços.

Hoje em dia, a tecnologia possui múltiplas funcionalidades, tanto no âmbito privado, quanto no público. Na esfera pública, encontra aplicação como aliada institucional do governo no aprimoramento da prestação dos serviços públicos, na transparência da gestão, na prestação de contas das políticas e na interação com o cidadão.

A internet é, ao mesmo tempo, disruptiva e, de certa forma, a virtualização dos ambientes de interação social é uma realidade recente, mas que vem se expandindo para as diversas áreas da vida, inclusive, a política. Por essa razão, faz-se importante conhecer essa dinâmica, para entender suas peculiaridades e, assim, desenvolver mecanismos que possibilitem que, também no ambiente digital, em que pesem as imperfeições existentes, haja

2 Eram excluídos do corpo de cidadãos em Atenas: as mulheres, os escravos e os estrangeiros. Apenas os homens adultos eram considerados. 
respeito e observância ao ordenamento e às instituições democráticas, em busca da promoção da cidadania.

Isso se deve, principalmente, em razão do crescimento da importância que as redes sociais vêm alcançando como instrumento de participação nos últimos anos.

Não se pode olvidar que o ambiente virtual se, por um lado, amplia e facilita o acesso da população às informações dos governos e aos serviços públicos, reduz distâncias, derruba barreiras da burocracia estatal e estimula a mobilização e a pressão sobre os poderes públicos, por outro lado, potencializa a disseminação da desinformação, tornando as pessoas mais vulneráveis e manipuláveis e, com isso, provoca a polarização. Esses últimos fatores afetam negativamente a democracia.

Nesse cenário, é possível afirmar que, a partir do surgimento das novas tecnologias de comunicação, houve alteração na dinâmica do exercício da cidadania na sociedade brasileira?

No processo eleitoral, os recursos tecnológicos também são utilizados, seja pela Justiça Eleitoral, seja pelos candidatos, para fazer campanha, como também e pelos próprios cidadãos, para, por exemplo, manifestarem apoio a algum candidato ou a algum partido político. Além dessas situações, atualmente os governantes têm utilizado as mídias digitais para se comunicar com os governados.

Assim, considerando a expressiva adesão aos dispositivos e ferramentas das tecnologias digitais de comunicação e interação nas experiências, iniciativas e práticas políticas relacionadas à ideia ou às instituições democráticas é que Gomes (2016) reconhece esse fenômeno como democracia digital, também denominado de ciberdemocracia ou e-democracia.

Para este estudo utiliza-se o método dedutivo, por meio de uma análise que leva em conta os critérios que pressupõem a democracia, aplicando-se a eles a perspectiva do comportamento social de disseminação da internet, em especial das ferramentas de interação. Para tanto, utiliza-se o suporte teórico extraído da bibliografia especializada.

A abordagem se divide em dois capítulos, destinados, respectivamente, à verificação de como a democracia representativa contemporânea vem se posicionando diante do novo cenário de sociedade hiperconectada e também de que forma as plataformas digitais são canalizadas à política, pelos agentes políticos, sejam candidatos ou governantes, pelas instituições, tais como os partidos políticos e até mesmo pelos cidadãos.

O artigo faz também uma abordagem panorâmica da problemática do uso da internet para disseminar a desinformação, através da propagação de conteúdos equivocados, por meio 
de robôs, fato que tem colocado em risco a liberdade de consciência dos governados e afetado negativa e gravemente a democracia.

O estudo é relevante porque sua proposta envolve temática atual, evidenciada no contexto social brasileiro. Trata-se de assunto em avançada discussão e, em certa medida, disciplinado pela legislação pátria, merecendo, assim, a devida reflexão para que a internet venha agregar valor ao processo de escolha dos governantes e às instituições democráticas, em vez de ser uma ameaça à cidadania.

É possível verificar que já existe certa normatização e fiscalização estatal com relação à utilização do espaço cibernético para as práticas democráticas. Entretanto, muito se discute sobre os limites da atuação do Estado, de forma a que restem assegurados os direitos de liberdade e igualdade dos cidadãos. Nesse compasso, de igual relevância é a percepção de que, na conexão entre democracia e internet, questões relacionadas à inclusão e à educação também precisam ser aperfeiçoadas.

\section{AS PLATAFORMAS DIGITAIS E A AMPLIAÇÃO DO IDEÁRIO DEMOCRÁTICO}

A democracia é o regime político em que o aspecto de maior destaque consiste na evidência da participação popular, igualitária e livre, no direcionamento das diretrizes e nas decisões governamentais, atribuindo-lhes maior legitimidade. "É processo de participação dos governados na formação da vontade governativa", nas palavras de Bonavides (2001, p.57)

Velloso e Agra ensinam que esse regime possibilita uma zona de interação entre os órgãos de poder e a sociedade. Nesse sentido, o comportamento do cidadão não mais se resume a apenas aceitar as ordens estatais ou contestá-las, mas contempla também, na forma participativa, um espaço de construção conjunta entre os cidadãos e o Estado (VELLOSO e AGRA, 2018, p. 20).

Desse modo, tendo como pilar a premissa da livre participação popular, a teoria acerca do regime democrático desdobra-se, principalmente, nos modelos de democracia representativa ou indireta, democracia participativa ou semidireta e democracia deliberativa.

A democracia representativa ou indireta desenvolveu-se mais fortemente a partir do advento da sociedade moderna e, na essência, consiste no exercício do poder político, realizado, na forma indireta, através de representantes escolhidos pelo povo para se dedicar aos assuntos 
voltados ao bem comum ${ }^{3}$. Bonavides aponta alguns fatores que contribuem para a implantação da democracia representativa na modernidade, quais sejam: grande extensão territorial dos Estados, amplitude demográfica, organização e divisão do trabalho determinados pelo regime de produção capitalista, assim como as complexidades e pluralidades de valores, interesses e culturas que se constituíram ao longo da evolução da sociedade (BONAVIDES, 2006, p. 293 294).

Nesse sentido, o procedimento de escolha dos mandatários por meio de eleições livres e constantes consiste em uma característica elementar da democracia representativa, porém conforme explica David Runciman, o simples fato de haver eleições não é suficiente para definir um regime como democrático, é preciso que haja também políticos responsáveis, canais eficientes de comunicação e programas alternativos consistentes (RUNCIMAN, 2010, p. 28).

A teoria do modelo de democracia participativa ou semidireta surgiu, segundo registra Frank Cunningham, em meados de 1960, o termo tendo sido cunhado por Arnold Kaufman. Por democracia participativa concebe-se aquela em que há o fomento da máxima participação do cidadão. Essa teoria apega-se às formulações de Rousseau consubstanciadas no conceito de "vontade geral"4 e "do ser forçado a ser livre" $"$. Para os defensores desse modelo, a principal preocupação é de que seja promovida a democratização em todos os "sistemas políticos" - na família, no trabalho, nas escolas, nos bairros; por sua vez, também rebatem as críticas daqueles que apontam a apatia pública como um fator dificultador à concretização da democracia participativa, apontando como causa de tal desinteresse a falta de poder e a inefetividade dos fóruns de deliberação (CUNNINGHAM, 2009, p. 148-164).

Por sua vez, a democracia deliberativa, cujo maior expoente é Jürgen Habermas, adota uma visão instrumental de democracia, através da qual protege-se o cidadão de um eventual governo arbitrário, valorizando-se a autonomia individual e a participação política pelo uso da razão, em busca da verdade imparcial, por meio do poder comunicativo voltado ao consenso universal, sem exercício da coerção. Segundo explica Barreiros (2019, p. 130-131), esse pensamento democrático alicerça-se na "definição de prioridades e decisões públicas" em

3 Bonavides (2006, p. 293) relembra o pensamento de Montesquieu, um dos principais teóricos da democracia moderna, que defendia que "o povo era excelente para escolher, mas péssimo para governar".

4 Segundo Rousseau, vontade geral significa interesse comum, sendo, portanto, conceito diferente do que se entende como vontade de todos, pois esta última estaria relacionada ao interesse privado (CUNNINGHAM, 2009, p. 149-150).

5 Ainda para Rousseau, o conceito de "forçados a serem livres" refere-se a que os cidadãos são obrigados pelas leis do corpo político a agirem contra a liberdade natural para agirem de acordo com sua liberdade civil, pois, desse modo, agiriam verdadeiramente livres (CUNNINGHAM, 2009, p. 158). 
resultado de amplo debate público, pautado na premissa de "possibilidade de convencimento mútuo entre os participantes do processo político", sem que isso signifique uma disputa de concepções contrárias em que, ao final, haja vitorioso e derrotado. Para tanto, mencionado discurso público, bem como a deliberação dele decorrente, contarão com a mediação do direito.

O Brasil adota a democracia indireta, também chamada de representativa, porém o sistema constitucional pátrio incorpora alguns instrumentos típicos da democracia semidireta, tais como: referendo, plebiscito e iniciativa popular, albergados no art. 14, incisos I a III da Constituição Federal de 1988.

A Carta Política pátria adota a sistemática de representantes escolhidos através de eleições periódicas, pelo voto direto, secreto e o sufrágio universal, para o exercício de mandato eletivo nos Poderes Executivo e Legislativo. No Poder Executivo, o mandato eletivo admite uma reeleição. Já no Poder Legislativo, não há limite de mandatos.

Entretanto, para além dos modelos, os pressupostos da democracia não se restringem ao aspecto da política, ou seja, como diz Machado (2018, p. 15), "não é apenas possibilitar ao povo participar do processo de escolha dos governantes”. É possível, ainda, indicar a existência de desdobramentos da concepção tradicional para assinalar a concepção de democracia jurídica $^{6}$, democracia econômica $^{7}$, democracia ambiental ${ }^{8}$, democracia social ${ }^{9}$ e democracia digital $^{10}$. Neste ensaio, o objeto de estudo consiste nessa última concepção descrita, a democracia digital.

Com o surgimento da internet ampliaram-se as possibilidades de acesso a todo tipo de informação, muitas coisas que antes era preciso guardar na memória, muito conhecimento que antes era transmitido através da fala ou em documentos impressos, hoje podem ser instantaneamente acessados em smartphones ou laptops.

Por seu turno, a democracia digital possui ampla dimensão, refere-se não somente ao espectro da participação popular no processo de escolha dos governantes, mas evidencia-se quando há a utilização de plataformas digitais nas mais diversas áreas. As principais são as

6 Entendimento que diz respeito a igualdade de todos perante a lei em direitos e deveres.

7 Refere-se ao efetivo acesso do povo às riquezas e serviços do país.

8 Consiste na participação da sociedade de forma a ter influência significativa nas decisões das instâncias de poder envolvendo as ações públicas e privadas que afetam a qualidade ambiental, bem como a total transparência sobre tais questões.

9 Relaciona-se ao desenvolvimento de políticas voltadas a maior inclusão social e ao enfrentamento da desigualdade social.

10 Diz respeito ao emprego de dispositivos, aplicativos, ferramentas e tecnologias digitais de comunicação para reforçar, suplementar e corrigir aspectos das práticas de participação do povo no poder político (GOMES, 2016). 
ações de transparência envolvendo governos e instituições públicas, os serviços públicos, os processos de fiscalização, denominados atualmente de "accountability", os processos de deliberação “on-line”, bem como as iniciativas de mobilização e participação popular através das redes sociais, fomentando a ampliação do diálogo.

Por outro lado, os meios digitais de comunicação constituíram-se, em diversas situações, como espaço de difusão do ódio, ocasionando desentendimentos entre as pessoas.

$\mathrm{O}$ avanço tecnológico, em certa medida, suprimiu barreiras, anteriormente existentes, que dificultavam o acesso dos cidadãos aos assuntos governamentais. Em alinhamento com tais ditames, identifica-se, no Brasil, um ferramental legislativo que dá sustentação à matriz digital da democracia.

A esse respeito, como referência, cabe mencionar, por exemplo, a Lei de Acesso à Informação, Lei n. ${ }^{\circ} 12.527^{11}$, de 18 de novembro de 2011 , que estabelece aos órgãos e entidades públicas a obrigatoriedade de divulgação de informações que lhes digam respeito, através de sítios oficiais da rede mundial de computadores. No mesmo sentido, a Lei n. ${ }^{\circ}$ $13.460^{12}$, de 26 de junho de 2017, ao disciplinar a participação, proteção e defesa dos direitos dos usuários dos serviços públicos, oportuniza que, além da forma convencional, a manifestação, perante a administração pública, ocorra por meio eletrônico.

Cabe ainda assinalar que as diretrizes da democracia digital devem ser de observância por todos os poderes da República (Poder Executivo, Poder Judiciário e Poder Legislativo) e suas respectivas instituições, em todos os níveis da federação. Também as organizações sociais e representativas, tais como os partidos políticos, sobretudo pelo papel de instituição indispensável ao funcionamento da democracia que possuem, devem em suas relações internas prestigiar a difusão dos mecanismos de acesso e participação, por meios digitais, inclusive.

A adesão da democracia aos avanços tecnológicos pode levar a promoção da cidadania, através das potencialidades verificadas com: o aumento da transparência do Estado, com o incremento em termo de rapidez, eficiência e economia na prestação dos serviços, o aumento da proximidade entre representantes e cidadãos, pela pluralização da esfera pública, fomento à

11 Art. $8^{\circ}$ É dever dos órgãos e entidades públicas promover, independentemente de requerimentos, a divulgação em local de fácil acesso, no âmbito de suas competências, de informações de interesse coletivo ou geral por eles produzidas ou custodiadas. [...] $§ 2^{\circ}$ Para cumprimento do disposto no caput, os órgãos e entidades públicas deverão utilizar todos os meios e instrumentos legítimos de que dispuserem, sendo obrigatória a divulgação em sítios oficiais da rede mundial de computadores (internet).

12 Art. 10. A manifestação será dirigida à ouvidoria do órgão ou entidade responsável e conterá a identificação do requerente. $\S 4^{\circ}$ A manifestação poderá ser feita por meio eletrônico, ou correspondência convencional, ou verbalmente, hipótese em que deverá ser reduzida a termo. 
autonomia e à capacidade de escolha dos sujeitos, do fortalecimento de comunidades políticas e laços de solidariedade, pela emersão de novas formas de mobilização e participação política, transnacionalização de lutas sociais e de formas de resistência tática e cotidiana contra as inscrições estruturais do poder, bem como por viabilizar novas formas de ocupação do espaço urbano.

Diante da nova realidade social, advinda dos modernos recursos tecnológicos, que criou um novo modelo de espaço público de manifestação, interação e mobilização para os mais diversos assuntos, que é o espaço virtual, das redes sociais e mídias digitais, a política não ficou à margem desse movimento.

No tópico seguinte, propõe-se a discorrer sobre algumas expressões da seara da política que se utilizam da internet como instrumento de participação democrática, abordando, por conseguinte, alguns desdobramentos do fenômeno.

\section{A INTERNET COMO AMBIENTE DE CAMPANHA ELEITORAL E DE MOBILIZAÇÃO POLÍTICA-SOCIAL}

O processo de escolha dos governantes encontra disciplina na Constituição Federal e em legislação específica, ficando a administração e fiscalização desse processo a cargo da Justiça Eleitoral. Segundo as regras eleitorais, os candidatos dispõem de um período, prévio às eleições, para realizar campanha eleitoral, para, nesse interstício, em tese, propagar suas ideias e difundir suas crenças, a fim de persuadir o eleitorado, por meio da propaganda eleitoral.

O conceito de propaganda eleitoral, embora atualmente já tenha adquirido contornos mais modernos, em virtude do advento novas tecnologias, foi apresentado, por ocasião da decisão proferida na RRP n. ${ }^{\circ}$ 51/DF, Min. Fernando Neves, julgada em 6 de agosto de 1998, no sentido de compreender os atos destinados a influenciar diretamente no espírito do eleitor, mediante a realização de verdadeiros comícios públicos ou a utilização de material publicitário, tal como a distribuição de cartazes e santinhos, veiculação de matéria paga nos órgãos de comunicação, sempre com expresso pedido de apoio a determinada candidatura ou agremiação partidária.

Por seu turno, Castro (2012, p. 277) defende que toda vez que um político ou pretenso candidato se dirige ao eleitor com suas ideias a respeito de como administrar bem o interesse público, ele está sugestionando o votante na tomada de decisão a respeito de em quem votar, quando das eleições. 
O processo eleitoral é disciplinado pela Constituição Federal, pelas leis ordinárias e complementares e, ainda, por Resoluções do Tribunal Superior Eleitoral.

Considerando que o ordenamento constitucional brasileiro aderiu ao sistema de partidos como condição intermediária para acessar um cargo público eletivo, para que um cidadão possa submeter-se ao escrutínio popular como vistas ao exercício de mandato eletivo, deve, a princípio, ser filiado a partido político, pelo prazo da lei, escolhido em convenção e ter sua candidatura submetida à Justiça Eleitoral.

A organização em partidos políticos foi destacada como direito e garantia fundamental pela Constituição de 1988, sendo positivada no Capítulo V do seu Título II. No artigo 17 e parágrafos, instituiu-se garantia à autonomia partidária, prevendo-se regras, por meio de norma constitucional de eficácia limitada, os critérios de direito aos recursos do fundo partidário e de “acesso gratuito ao rádio e à televisão".

A despeito de, por ora, revogada a regulamentação da propaganda partidária políticoeleitoral no rádio e na televisão, pela Lei n. ${ }^{\circ} 13.487$, de 2017, os filiados aos partidos podem realizar propaganda político-eleitoral intrapartidária, nos termos do art. $36, \S 1^{\circ}$, da Lei das Eleições.

A propaganda eleitoral, além de possuir previsão Constitucional, também recebe regulamentação da Lei n. ${ }^{\circ}$ 9.504/97, conhecida como Lei das Eleições.

Nas palavras de Machado (2018, p. 289), a propaganda eleitoral é, muitas vezes decisiva no resultado das eleições e nos rumos políticos do país.

Tradicionalmente, a televisão e o rádio constituem os meios mais poderosos de propaganda eleitoral. A definição do êxito de uma eleição costumava ser diretamente proporcional ao tempo de propaganda no rádio e na televisão. Também, era fator determinante para o sucesso nas urnas, o fato de o candidato possuir afinação com os meios de comunicação televisionados. À guisa de exemplo desse cenário, pode-se citar o primeiro presidente eleito após a redemocratização, até então, o pouco conhecido político alagoano, Fernando Collor, que, com o apoio da mídia televisiva e sob o slogan "caçador de marajás", venceu, no primeiro turno das eleições, derrotando políticos consagrados e de passado inatacável, como Ulysses Guimarães e Mário Covas (CARVALHO, 2018, p. 206).

Nessa época, era com o início do horário eleitoral gratuito que as campanhas tornavam-se mais acirradas e, geralmente, eram aqueles candidatos, cujo partido ou coligação possuía maior tempo de propaganda, que conseguiam ser eleitos. 
Outra peculiaridade do horário eleitoral gratuito é o sentimento que, muitas vezes, esse meio de propaganda desencadeia nas pessoas. Para alguns, seria motivo de rejeição, momento de desligar a televisão. Para outros, momento de zombar e fazer piada com a atuação e a desenvoltura de muitos políticos na televisão. Pelo que se percebe, não são maioria os que, realmente, avaliam com seriedade as palavras proferidas pelos políticos, as promessas de campanha, porventura apresentadas. Sem falar que ainda existem alguns políticos que nem fazem uma propriamente campanha propositiva, mas, ao invés, encenam caricaturas e personagens e, com isso, desencadeiam o chamado "voto de protesto".

A política no Brasil vem mudando nos últimos anos, em virtude da disseminação da cultura de comunicação por meio das redes sociais na sociedade brasileira. As mídias digitais têm modificado o espaço público e a forma como as pessoas interagem entre si, por isso, não assusta que também tenha se modificado a forma como os cidadãos se relacionam com o poder público e exerçam seu papel na democracia.

Desde a campanha eleitoral de 2010, a forma de fazer campanha eleitoral tem sofrido mudanças. Com o advento das novas tecnologias, com a disseminação das mídias de interações digitais, tais como as redes sociais Facebook, Twitter, Instagram, YouTube e, pouco tempo depois, o Whatsapp, a maneira tradicional de fazer política vem cedendo lugar para as ferramentas digitais, alterando, não apenas, ambiente de maior ênfase da propaganda eleitoral, mas também o cenário de discussão dos debates políticos.

A utilização em massa dessas novas tecnologias de comunicação impulsionou, inclusive, uma alteração na legislação eleitoral, trazida pela Lei n. ${ }^{\circ}$ 12.034/2009, que adaptou a Lei n. ${ }^{\circ}$ 9.504/97, passando a contemplar uma seção específica para tratar da propaganda eleitoral na internet. A cada eleição, o legislador promove outras alterações na pretensão de afinar a lei eleitoral às práticas da internet, em especial, das redes sociais. A mais recente, ocorreu na reforma de 2017, pela Lei n. ${ }^{\circ} 13.488$, de 2017, em que foi autorizado o impulsionamento de conteúdo por parte de candidato, do partido político ou da coligação (RAIS, 2018).

Essa sistemática de impulsionamento de conteúdo arregimentou alguns admirados, entretanto impulsionou alguns posicionamentos críticos, notadamente, diante da invasão dos "bots", robôs programados para replicar conteúdos enganosos ou para se passarem por humanos nas discussões das redes sociais, principalmente, no Twitter. Tais robôs são "softwares" 
que agem de forma autônoma na internet, simulando o comportamento humano e enviando mensagens através de perfis genéricos ou falsos.

Não é de se olvidar que as redes sociais, além de terem revolucionado a forma de interação, comunicação e relacionamento interpessoal, também viraram espaço de articulação e discussão política. Muitas pessoas que antes eram alheias aos assuntos políticos eleitorais, agora, têm interesse por publicar, compartilhar e, em algumas ocasiões, comentar, como especialistas.

A Internet tem essa capacidade de transformar o cidadão em um "potencial produtor de notícias ou de opiniões". Milhões de pessoas tradicionalmente excluídas, com raras oportunidades disponíveis, passaram a ter acesso facilitado aos espaços de informação. Consiste em uma oportunidade libertadora e democrática, pelo que resta superada uma época em que apenas poucos podiam expressar suas opiniões na via impressa, TV ou rádio (MACEDO JÚNIOR, 2018, p. 133).

Em que pese o viés emancipatório inerente à tecnologia, é preciso ter cuidado para que esse movimento que congrega as mais diversas perspectivas e opiniões sobre determinado tema não venha afetar o aspecto científico de como devem ser abordados determinados assuntos. O incentivo à participação política e ao engajamento do cidadão nos negócios da comunidade é uma meta a ser perseguida em uma democracia, porém deve-se ter o cuidado para que ondas de populismo e fundamentalismo não influenciem as pessoas através do medo e da raiva, em vez de promover um debate sensato, descreditando as instituições democráticas e substituindo os especialistas pela sabedoria das multidões (KAKUTANI, 2018, p. 12).

Observa-se que tem ganhado espaço nos ambientes virtuais, principalmente, a difusão de teorias que, sem nenhum fundamento empírico, pretendem desconstruir a ciência. Com esse perfil, é possível citar os "terraplanistas", as teorias que refutam a evidência do aquecimento global e os grupos antivacinas. Keen apud Kakutani (2018, p. 39) alerta para o fato de que a internet, nos últimos tempos, não apenas democratizou a informação de maneira inimaginável, como também está fazendo com que a "sabedoria das multidões" ocupe o lugar do conhecimento legítimo, embaçando perigosamente os limites entre fato e opinião, entre argumentação respaldada e mera especulação.

A televisão, que antes era um dos principais canais de entretenimento das pessoas, perdeu muito espaço. Hoje é muito mais atrativo ser o próprio protagonista da notícia, estar em evidência, através de uma postagem, por meio do compartilhamento de um vídeo ou de uma 
publicação, seja entre a rede de contatos ou mesmo para um número indeterminado de pessoas, como acontece nos blogs e canais do YouTube.

Em política, as plataformas de conexão e interação virtual vêm demonstrando ser um novo instrumento de empoderamento do cidadão comum, trazendo um ganho democrático em razão da formação de novos públicos de comentário social, através de novos meios e oportunidades de publicar opiniões e de sentir a reação dos outros a elas. Os fluxos de interação nos ambientes digitais na Internet são, hoje, um elemento muito importante para a política em geral (GOMES, 2016).

Diante desse cenário de proliferação do uso das mídias digitais pelas pessoas, os políticos passaram a ocupar esses espaços para fazer campanha, de forma que, assim, pudessem alcançar a atenção do eleitorado. Além disso, novos atores políticos entraram em cena, novos rostos, pessoas que não possuem tradição e história na política, mas que detêm o conhecimento do manuseio das plataformas e dispositivos de comunicação digital passaram a fazer campanha eleitoral de forma mais atrativa, conquistando o eleitorado e, dessa forma, um cargo público eletivo.

Com isso, as mídias tradicionais, como o rádio e a televisão perderam relevância, pois embora contem com preciosos recursos de visibilidade de que necessita a comunicação estratégica, os meios digitais se sobressaem, pois além de serem mais baratos, são considerados mais eficazes. No ambiente virtual, todo cidadão pode ser um autor, jornalista ou um editor. Teoricamente a um custo muito baixo todos podem divulgar palavras, imagens ou sons que chegarão a bilhões de outras pessoas ao redor do mundo (MACEDO JÚNIOR, 2018, p. 135). Diogo Rais (2018, p. 157) relata que um usuário individual sem histórico ou reputação pode, em alguns casos, alcançar tantos leitores quanto a Fox News, a CNN ou o New York Times.

Além disso, a televisão e o rádio, em determinados aspectos, possuem restrições, não podem ser utilizados como meio de mobilização e de monitoramento da campanha. Já as arenas dos meios sociais digitais podem integrar tudo: comunicação estratégica, monitoramento, mobilização, engajamento e participação.

Nas redes sociais, é possível mensurar, em um determinado período de tempo, a quantidade de compartilhamento de mensagens, a utilização de "hashtags", os perfis mencionados e as palavras mais utilizadas, permitindo ao candidato aferir, a partir do resultado obtido, a popularidade, o nível de influência e aceitação de determinadas opiniões e ações, perante a opinião pública, mesmo antes do início da campanha eleitoral. E, assim, adequar sua 
retórica de forma que seja mais atrativa aos eleitores, buscando enfatizar, na campanha eleitoral, as qualidades, as ideologias, as promessas e as propostas que se alinham aos anseios dos eleitores. Nas palavras de Daniel Innerarity (2017, p. 100), a política é a arte de procurar a aquiescência num meio de confronto público, para o qual é necessário utilizar palavras que representem algo que é apreciado pelo destinatário.

Outro aspecto negativo da propaganda eleitoral difundida exclusivamente pelas emissoras de televisão consiste no reduzido espectro de abrangência, em especial, nas eleições municipais, porque, segundo relata Rais (2018, p. 160), somente os eleitores dos 5\% (cinco por cento) dos municípios brasileiros conseguem ter contato com seus possíveis candidatos por meio da televisão. Os demais $95 \%$ (noventa e cinco por cento) ficam sem poder assistir a campanha de seus possíveis candidatos, pois nos televisores desses eleitores é transmitida a propaganda eleitoral do município onde fica localizada a sede da emissora.

Os representantes são eleitos com a finalidade de que atuem, por meio do mandato, em favor dos interesses da sociedade. Entretanto, muitas vezes, ocorre o contrário, acabam por configurar uma decisão política apartada da sociedade ou esfera civil. A sociedade, em contrapartida, organiza-se e mobiliza-se com o objetivo de contestar, bem como reivindicar a retomada do alinhamento entre os governados e os governantes.

Nesse contexto, as redes sociais também foram utilizadas, de forma inédita e pouco convencional, como espaço de organização e mobilização. Movimentos sociais formaram-se ao redor do mundo. O primeiro movimento político que se notabilizou por contar com a ajuda da internet para ganhar visibilidade aconteceu no México, em janeiro de 1994. Todavia foi com o surgimento e a expansão das redes sociais, notadamente, a partir dos anos de 2010, que a internet se consolidou também como uma ferramenta política na organização de movimentos de massas, utilizada para viabilizar protestos contra velhas autocracias, bem como contra medidas de austeridades impostas pelos governos e organismos multilaterais.

Em vários países, eclodiram diversos movimentos, em diferentes graus, que fizeram uso das redes sociais como ferramenta de engajamento, pode-se citar a Revolução de Jasmim, na Tunísia entre 2010 e 2011; guerra da Líbia e convulsões no Bahrein, na Síria e na Arábia Saudita, conhecidos como Revolução Árabe; os protestos na Grécia, o movimentos como Geração à Rasca, Movimiento 15-M e Indignados, respectivamente, em Portugal, Espanha e Itália, entre outros (GOMES, 2016, p. 368). 
Já no âmbito nacional, emergiu uma onda de manifestações, ocorrida na segunda semana de junho de 2013. Inicialmente, esses movimentos populares possuíam como objetivo a contestação do aumento da tarifa de ônibus, mas depois ampliaram-se para uma dimensão que reunia uma gama de descontentamentos da sociedade em relação a falhas nas prestações dos direitos sociais, pelo Estado, bem como insatisfações em relação à classe política, em geral.

Uma peculiaridade comum aos movimentos ocorridos ao redor do mundo, mas que os diferenciam dos movimentos convencionais, foi a novidade trazida pela utilização das redes sociais digitais em direta conexão entre os protestos de ruas.

Outra característica própria dos movimentos sociais na era das redes sociais consistiu na atuação protagonista de pessoas mais jovens, mais socialmente incluídas do que a média da população, oriundas de um contexto de baixo engajamento cívico e de pouca participação política. Porém, o aspecto que realmente se destacou nesses eventos foi o amplo uso de tecnologia e ambientes digitais como base de articulação, como meio de divulgação e denúncia, além de forma de acompanhamento e discussão (GOMES, 2016, p. 372).

Entretanto, apesar do incremento da participação política com o advento tecnologia das mídias digitais, ainda, é de significante evidência a questão da exclusão social no Brasil, o que reflete em situações de exclusão digital.

A Internet é um meio de comunicação democrático por excelência (RAIS, 2018, p. 47), mas para que haja essa interação igualitária é necessários que as pessoas tenham acesso à rede mundial de computadores e recebam a adequada alfabetização digital.

A inclusão digital não se restringe a uma simples política pública de distribuição de computadores, trata-se de um conceito mais abrangente que envolve, ainda, o poder de comunicação, de produção de conhecimentos e de organização por meio do uso das tecnologias e a internet. Em sua verdadeira acepção, a inclusão digital tem como escopo tornar os sujeitos autores da sua própria realidade, participantes e produtores da transformação social por meio do uso das tecnologias e da internet (MACHADO E RIVIERA, 2017).

Ocorre que apesar de as mídias digitais poderem potencializar a emersão de novas formas de mobilização e participação política, no Brasil, ainda, há as barreiras impostas pela exclusão e pelo analfabetismo a serem enfrentadas.

Segundo a Agência Brasil, o Brasil ocupa o quarto lugar na lista dos países com maior número de usuários de Internet. De acordo com dados do IBGE, em maio de 2018, o Brasil chegou à marca de 209 milhões de brasileiros. Destes, 139 milhões são usuários da internet, o 
que representa acesso de $66 \%$ do total da população. O número revela o quadro de "exclusão digital" de 34\% da população. Entretanto, a inclusão precisa ser mais igualitária. Ainda com base nos indicadores da pesquisa do IBGE, quem mais utiliza a internet são jovens, escolarizados, empregados, com maior renda e residentes em áreas urbanas e, em alguns estados da federação, o acesso através de celulares supera o por microcomputador.

Outro fator negativo é o analfabetismo permanecer em níveis constantes, segundo pesquisa divulgada pelo IBGE, a taxa de analfabetismo no país ficou estagnada entre 2016 e 2017. O Brasil encerrou o ano de 2017 com 11,5 milhões de analfabetos, 300 mil a menos do que tinha no ano anterior. A pesquisa expõe também a desigualdade regional no acesso à educação. Enquanto o Sudeste e o Sul têm a menor taxa de analfabetismo, de 3,5\%, o indicador no Nordeste é muito superior, de $14,5 \%$ em 2017. Não houve variação expressiva entre os anos de 2016 e 2017.

Uma pesquisa do IBOPE também apontou a relevância crescente da Internet como fonte de informação no período eleitoral.

Outra questão que precisa ser enfrentada e que, de certa forma, está relacionada muito proximamente com o mundo digital, trata-se das "fake news". Em geral, ora materializam-se como notícias falsas, ora como reportagens deficientes ou parciais, ora como agressão a alguém ou a alguma ideologia (RAIS, 2018, p. 68).

Pode-se atribuir como as principais causas para o fenômeno da "fake news": A descentralização da informação; ambiente de forte polarização política; a crise de confiança nas instituições tradicionais e o fortalecimento de uma visão de mundo que relativiza a verdade.

A “fake news" causa significativos danos à democracia. É preciso, portanto, que haja a atuação contundente e efetiva das Instituições da República, em especial, da Justiça Eleitoral, para que seja desenvolvida uma devida regulamentação, bem como uma fiscalização eficaz no combate desse ruído democrático.

Raquel Machado (2018, p. 314) alerta que é necessário um grande esforço fiscalizatório por parte da Justiça Eleitoral para coibir eventuais abusos e infrações, assim como é preciso que o cidadão tenha maturidade na avaliação dos conteúdos divulgados pelas mídias digitais para não se deixar envolver em "bolhas digitais" ou "câmaras de eco", que seriam uma espécie de oferta personalizada de informações com o condão de segregar as pessoas que compartilham da mesma opinião em ambientes digitais diversos daqueles que pensam 
diferentemente, prejudicando, desse modo, o espírito democrático e podendo conduzir a extremismos.

Nessa linha, Cass Sunstein sugere que a Internet pode, na prática, contribuir para o que ele chama de polarização de grupos (SUNSTEIN, 2007), uma vez que as pessoas permanecem, no ambiente virtual, fazendo parte de comunidades minoritárias de pensamento semelhante, não sendo confrontadas por outras ideias.

Em reforço ao que vem sendo dito até aqui, está consolidado o entendimento de que as "fake news" tem a função maior de trazer desinformação e poluir o debate político do que, propriamente, influenciar na decisão de voto dos eleitores. Isso porque, em relação aos eleitores pertencentes a um dos polos tem fraca influência. Talvez, possua algum poder em relação os eleitores indecisos ou sem convicção absoluta em relação a escolha de um candidato. Ademais, como discorre Almeida (2018, p. 169), só um ambiente sadio e livre de ódio poderá permitir a participação livre da sociedade.

Para Rais (2018, p. 165) não é saudável para a democracia destinar ao Estado o domínio do conteúdo das mensagens. Salutar seria adotar-se uma agenda positiva, em que o Estado e a sociedade poderiam, cada vez mais, incentivar o empoderamento dos usuários para que chequem, escolham e sejam curadores dos conteúdos, mas, para isso ser possível, é necessário mais informação, educação e liberdade. $O$ autor sustenta, ainda, que o fortalecimento da imunidade dos indivíduos através da educação digital pode ser a melhor estratégia para vencer os desafios da desinformação.

Pelo que se percebe, o uso das mídias sociais não repercute somente na forma como os candidatos se conduzem durante a campanha eleitoral, especificamente, no desenvolvimento da propaganda eleitoral, assim como, nas manifestações espontâneas das pessoas. Também é utilizada como mecanismos de governo. O atual governo brasileiro tem se utilizado das manifestações e posicionamentos exteriorizados através das redes digitais como uma espécie de termômetro, para sinalizar a repercussão das decisões e das políticas públicas adotadas.

\section{CONSIDERAÇÕES FINAIS}

A partir das considerações delineadas ao logo deste estudo foi possível aferir a consolidação da rede mundial de computadores como modelo de espaço público de interação social. Figurando, portanto, ambiente, por meio do qual os mais diversos assuntos de interesse da sociedade são abordados, entre eles a política e seus desdobramentos, quais sejam 
propaganda eleitoral, participação e mobilização popular, bem como fiscalização e acompanhamentos das ações governamentais.

Nesse sentido, é que se pode perceber que o avanço tecnológico contribuiu para uma maior democratização da política, porque estimulou não só um movimento por parte dos poderes da República de possibilitar maior transparência aos dados das instituições, assim como, de viabilizar acesso facilitado aos serviços públicos. Como também, mudou a forma de participação política, ao possibilitar aos cidadãos posicionarem-se na condição de protagonistas do processo.

Para esse fenômeno, atribui-se a legenda de Democracia Digital, que não se trata de um modelo de democracia, mas de uma nova forma de manifestação, através da utilização das mídias digitais.

A partir de então, diante dessa perspectiva de potencialização democrática, até mesmo o processo de escolha dos governantes sofreu mudanças, seja pelo advento da propaganda na internet, seja pelo papel de destaque que essa forma de propaganda vem alcançando, destituindo, inclusive, a influência de meios tradicionais, como o rádio e a televisão. Sem falar no impacto das redes sociais no modo como os governantes, durante o exercício do mandato, tem conduzido as políticas públicas e se comunicado com a opinião pública.

Entretanto, em que pese essa pluralização proporcionada pela inovação tecnológica fomentar os festejados princípios de liberdade e igualdade, valores tão caros para a democracia, há de ter o cuidado para que a manipulação de dados, a desinformação e, em tão grave medida, a desconstrução, sem fundamento científico, de teorias consolidadas, não venham macular livre consciência dos cidadãos.

Entretanto, para além da discussão se as novas tecnologias de comunicação podem, de fato, alterar para melhor as possibilidades da cidadania na sociedade brasileira, as barreiras impostas pela exclusão social e, por seu turno, digital, assim como pelo analfabetismo, que assolam nosso povo, precisam ser superados para, então, despontar a cidadania plena no horizonte.

\section{REFERÊNCIAS}


ALMEIDA, Marcos Lourenço Capanema de. O discurso de ódio na propaganda política eleitoral brasileira. In: PEREIRA, Rodolfo Viana (Org.) Direitos políticos, liberdade de expressão e discurso de ódio. Belo Horizonte: IDDE, 2018.

AFRANIO, Cláudia; VALPATO, Eliane Bavaresco. Integração democrática na era da internet. Paraná Eleitoral, Curitiba, v. 6, n. 1, p. 87-102, 2016.

BARREIROS NETO, Jaime. Teorias da democracia. Coleção Democracia e Reforma Política. Salvador: Faculdade Baiana de Direito, 2019.

BONAVIDES, Paulo.Teoria Constitucional da Democracia Participativa:por um Direito Constitucional de luta e resistência, por uma Nova Hermenêutica, por uma repolitização da legitimidade. São Paulo: Malheiros, 2001.

BONAVIDES, Paulo. Ciência Política. 12 ed. São Paulo: Malheiros, 2006.

BRASIL. Constituição (1988). Constituição da República Federativa do Brasil, Brasília, DF, Senado, 1988.

BRASIL. Lei n ${ }^{\circ}$ 9.504, de 30 de setembro de 1997. Diário Oficial da União, Poder Legislativo, Brasília, DF.

BRASIL. Tribunal Superior Eleitoral (TSE), Recurso em Representação (RRP) n. ${ }^{\circ}$ 51/DF, Min. Fernando Neves, Brasília, DF, 6 de agosto de 1998. Lex: jurisprudência do TSE, Poder Judiciário, Brasília, DF.

CASTELLS, Manuel. Ruptura: uma crise da democracia liberal. Tradução Joana Angélica d'Avila Melo. 1. ed. Rio de Janeiro: Zahar, 2018.

CASTRO, Edson de Resende. Curso de direito eleitoral. 6. ed. rev. atual. Belo Horizonte: Del Rey, 2012.

CARVALHO, José Murilo. Cidadania no Brasil: o longo caminho. 24. ed. Rio de Janeiro, Civilização Brasileira, 2018.

CUNNINGHAM, Frank. Teorias da democracia: uma introdução crítica. Tradução Delmar José Volpato Dutra. Porto Alegre: Artmed, 2009.

DAHL, Robert A. Sobre a democracia. Tradução Beatriz Sidou. Brasília: Editora Universidade de Brasília, 2001.

GOMES, Wilson. Nós somos a rede social! In: MENDONÇA, Ricardo Fabrino; PEREIRA, Marcus Abílio; FILGUEIRAS, Fernando (Orgs.). Democracia digital: publicidade, instituições e confronto político. Belo Horizonte: Editora UFMG, 2016.

GOYARD-FABRE, Simone. O que é democracia? A genealogia filosófica de uma grande aventura humana. Tradução Cláudia Berliner. São Paulo: Martins Fontes, 2003. 
INNERARITY, Daniel. A política em tempo de indignação: a frustração popular e os riscos para a democracia. Tradução de João Pedro George. Rio de Janeiro: LeYa, 2017.

KAKUTANI, Michiko. A morte da verdade. Tradução de André Czarnobai e Marcela Duarte. 1. ed. Rio de Janeiro: Intrínseca, 2018.

MACEDO JUNIOR, Ronaldo Porto. Fake News e as novas ameaças à liberdade de expressão. In: ABBOUD, Georges; NERY JUNIOR, Nelson; CAMPOS, Ricardo (Orgs.). Fake News e Regulação. São Paulo: Thomson Reuters Revista dos Tribunais, 2018 (Col. Direito e Estado em Transformação).

MACHADO, Raquel Cavalcanti Ramos. Direito Eleitoral. 2. ed. rev., atual. E ampl. São Paulo: Atlas, 2018.

MACHADO, Raquel Cavalcanti Ramos; RIVERA, Laura Nathalie Hernandez. Democratização na era digital: desafios para um diálogo consciente e igualitário. Revista Brasileira de Políticas Públicas, Brasília, v. 7, n. 3, p. 606-616, dez. 2017.

MELO, Liana. 10 perguntas para Runciman. ÉPOCA edição político-literária, Rio de Janeiro: n. 1061, p. 26-30, 29 out. 2018.

RAIS, Diogo. Desinformação no contexto democrático. In: ABBOUD, Georges; NERY JUNIOR, Nelson; CAMPOS, Ricardo (Orgs.). Fake News e Regulação. São Paulo: Thomson Reuters Revista dos Tribunais, 2018 (Col. Direito e Estado em Transformação).

RAIS, Diogo; FALCÃO, Daniel. GIACCHETTA, André Zonaro; MENEGUETTI, Pamela. Direito Eleitoral Digital. RAIS, Diego (Coord.). São Paulo:Thomson Reuters Revista dos Tribunais, 2018.

SUNSTEIN, Cass R. Republic.com.2.0. Princeton: Princeton University Press, 2007a.

VELLOSO, Carlos Mário da Silva; AGRA, Walber de Moura. Elementos de direito eleitoral. 6. ed. São Paulo: Saraiva Educação, 2018. 